\title{
Association between promoter polymorphisms of nuclear factor-erythroid 2-related factor 2 gene and peptic ulcer diseases
}

\author{
TOMIYASU ARISAWA, TOMOMITSU TAHARA, TOMOYUKI SHIBATA, MITSUO NAGASAKA, \\ MASAKATSU NAKAMURA, YOSHIO KAMIYA, HIROSHI FUJITA, DAISUKE YOSHIOKA, \\ YUKO ARIMA, MASAAKI OKUBO, ICHIRO HIRATA and HIROSHI NAKANO
}

Department of Gastroenterology, Fujita Health University School of Medicine, 1-98 Dengakugakubo, Kutsukake-cho, Toyoake 470-1192, Japan

Received July 26, 2007; Accepted September 3, 2007

\begin{abstract}
Transcription factor Nrf2 regulates the expression of detoxifying and antioxidant genes. Three promoter polymorphisms of this gene have been identified. We attempted to clarify the association of these polymorphisms with the development of peptic ulcer diseases. The study was performed with 384 stocked DNAs obtained from subjects with no evidence of gastric malignancy. In all 384 DNAs, 77 and 48 were obtained from gastric and duodenal ulcer patients, respectively. By an unadjusted analysis, infection with Helicobacter pylori (H. pylori), male gender and the -686 / -684 G/G carrier (OR, 2.52; 95\% CI, 1.19-5.45; p=0.016) were associated with a significantly increased risk for developing gastric ulcer, whereas the -686/-684 A/G homozygote was linked to a significantly reduced risk for developing gastric ulcer (OR, 0.26; 95\% CI, 0.099-0.67; $\mathrm{p}=0.0055)$. On the other hand, infection with $H$. pylori and male gender were significantly associated with the development of duodenal ulcer, whereas Nrf2 promoter polymorphisms were not. By the analysis, after adjustment for age, gender, non-steroidal anti-inflammatory drug/aspirin use and $H$. pylori infection status, the $-686 /-684$ A/G homozygote was associated with a significantly reduced risk for gastric ulcer (OR, 0.25; 95\% CI, 0.088-0.73; p=0.011). Our results suggest that promoter polymorphisms of the Nrf2 gene are associated with the susceptibility to gastric ulcer.
\end{abstract}

\section{Introduction}

One of the important factors that influences Helicobacter pylori (H. pylori)-induced gastric inflammation is oxidative stress (1). Reactive oxygen species (ROS) are believed to be

Correspondence to: Dr Tomiyasu Arisawa, 1-98 Dengakugakubo, Kutsukake-cho, Toyoake 470-1192, Japan

E-mail: tarisawa@fujita-hu.ac.jp

Key words: nuclear factor-erythroid 2-related factor 2, promoter polymorphism, peptic ulcer involved in promoting inflammation and in regulating the expression of oncogenes (2). Enhanced ROS production has been demonstrated in endoscopic biopsy samples from the duodenum and stomach of $H$. pylori-infected patients $(3,4)$. There seems to be no doubt that ROS have an important role in the development of gastric inflammation induced by $H$. pylori infection. Recent studies have suggested that nuclear factor-erythroid 2-related factor 2 (Nrf2) is an important regulator of genes induced by oxidative stress, such as heme oxygenase- 1 and peroxiredoxin 1 (5), and that susceptibility to hyperoxia is tightly linked to the nrf2 locus (6). It has been also reported that the impaired defenses against oxidative stress of nrf2 null mice showed substantially decreased clearance of ROS (7). More recently, three polymorphisms of the promoter region (positions, -686, -684, and -650) of the human Nrf2 gene were identified (8). This study did not reveal a close connection between the risk of inflammatory diseases and these polymorphisms, but it appears important to examine the link between Nrf2 polymorphisms and oxidative stress-related diseases.

On the other hand, it is well known that Helicobacter pylori infection, as well as non-steroidal anti-inflammatory drug (NSAID/aspirin) use, are major contributing factors to the development of peptic ulcer (9). Infection with $H$. pylori usually leads to persistent colonization and chronic gastric inflammation. However, only one group of infected patients suffers the gastro-duodenal ulcer diseases. There are marked differences in the extent of inflammation among $H$. pyloriinfected patients, so clinical consequences only develop in a small subgroup. The course of $H$. pylori infection may be influenced by genetic pre-disposition and host immunity, as well as by bacterial virulence factors. Inflammation induced by $H$. pylori is implicated in gastric mucosal damage and is characterized by severe granulocytic and lymphocytic infiltration (10). We have already demonstrated that promoter polymorphisms of the Nrf2 gene were significantly associated with the infiltration of inflammatory cells into gastric mucosa, either independently or by interacting with $H$. pylori infection (11). Since all subjects with severe gastric inflammation do not suffer peptic ulcer, a relationship between Nrf2 promoter polymorphisms and the development of peptic ulcer remains unclear. 
In the present study, we attempted to clarify the associations of G-686A, G-684A and C-650A polymorphisms in the Nrf2 gene promoter with the development of gastro-duodenal ulcer.

\section{Patients and methods}

Clinical samples. We randomly selected 400 samples from our stocked DNA obtained from patients who were enrolled at the Endoscopy Center of Fujita Health University Hospital in 2006. All patients underwent upper gastro-duodenal endoscopy and, in some of them, biopsy specimens were taken from antral mucosa. Parts of each specimen were fixed in $10 \%$ buffered formalin and embedded in paraffin, while the other parts were immediately frozen and stored at $-80^{\circ} \mathrm{C}$. Genomic DNA was isolated from frozen antral biopsy specimens by digestion using proteinase $\mathrm{K}$ or extracted from peripheral blood using FlexiGene DNA kit (Qiagen $\mathrm{GmbH}$, Hilden, Germany). All histological diagnoses were made at the Department of Pathology of our hospital. The severity of chronic gastritis was also classified according to the updated Sydney system by a pathologist who had no access to any clinical information (12).

Finally, the study population comprised 384 subjects with no neoplastic lesions whose DNA was clearly analyzed. H. pylori infection status was assessed by serology, histological examination, or the urea breath test. Patients were diagnosed as having the infection when at least one of the diagnostic tests was positive. The Ethics Committee of Fujita Health University School of Medicine approved the protocol, and written informed consent was obtained from all of the participating subjects.

Genotyping of polymorphisms. Nrf2 polymorphisms were genotyped by PCR-SSCP as reported previously $(11,13)$. We employed the nested PCR reaction because the quality of the PCR-SSCP depends on the purity of the reactants. Primer sequences for the PCRs are as follows: 1st PCR forward, 5'aaacgattacagcatgttgtggt-3' (NRF2F); reverse, 5'-tgatttggagttg cagaacctt-3' (NRF2R); 2nd PCR for -686/-684 forward, 5'-gct ctgggtgggcaatactg-3' (NRF2-AF); reverse, 5'-cgcagtcaccctga acgc-3' (NRF2-AR); and for -650 forward, 5'-tgactgcgaacacg agctg-3' (NRF2-BF); reverse, 5'-ggctaaagatttggacccagac-3' (NRF2-BR).

The first PCR was carried out using a pair of primers (NRF2F and NRF2R) in a volume of $20 \mu \mathrm{l}$ containing $0.1 \mu \mathrm{g}$ of genomic DNA. The DNA was denatured at $95^{\circ} \mathrm{C}$ for $5 \mathrm{~min}$, followed by 35 cycles at $95^{\circ} \mathrm{C}$ for $30 \mathrm{sec}, 62^{\circ} \mathrm{C}$ for $40 \mathrm{sec}$, and $72^{\circ} \mathrm{C}$ for $60 \mathrm{sec}$, with a final extension at $72^{\circ} \mathrm{C}$ for $5 \mathrm{~min}$. The second PCR was carried out in a volume of $20 \mu 1$ containing $2 \mu \mathrm{l}$ of the first PCR product diluted 100-fold with distilled water as a sample using two pairs of primers (NRF2AF, -AR and NRF2-BF, -BR for bases $-686 /-684$ and -650 , respectively). The DNA was denatured at $95^{\circ} \mathrm{C}$ for $5 \mathrm{~min}$, followed by 35 cycles at $95^{\circ} \mathrm{C}$ for $15 \mathrm{sec}, 62^{\circ} \mathrm{C}$ for $30 \mathrm{sec}$, and $72^{\circ} \mathrm{C}$ for $45 \mathrm{sec}$, with a final extension at $72^{\circ} \mathrm{C}$ for $5 \mathrm{~min}$.

Then $2 \mu \mathrm{l}$ of the 2 nd PCR product was denatured with $10 \mu 1$ of formamide (Sigma-Aldrich Co., St. Louis, MO, USA) for $5 \mathrm{~min}$ at $90^{\circ} \mathrm{C}$. SSCP was carried out at 6 or $18^{\circ} \mathrm{C}$ using a GenePhor DNA separation system with GeneGel
Excel 12.5/24 (Amersham Biosciences Corp., USA). The denatured single-stranded DNA bands were detected using a DNA Silver Staining kit (Amersham Biosciences Corp.).

Statistical analysis. Age and the updated Sydney system scores were expressed as the mean \pm SD. The mean ages between 2 groups were compared with the Student's t-test. The male/female ratio and $H$. pylori positivity were compared with the Chi-squared test. The allele counts were also compared between ulcer and non-ulcer group using the Chisquare test. The strength of association between allelic frequencies and the disease was assessed by calculating the odds ratio (OR) and 95\% confidence intervals (CI). Adjusted ORs were calculated with the use of logistic regression analysis after adjustment for age, gender, NSAID/aspirin use and $H$. pylori infection status. The assessment of the difference of each updated Sydney system score among genotypes was performed using the Mann Whitney U-test. For all analyses, the level of significance was set at $\mathrm{p}<0.05$.

\section{Results}

The characteristics of the subjects and the frequencies of genotypes. The characteristics of the subjects and the frequency of each Nrf2 promoter polymorphism in our subjects are shown in Table I. In all 384 subjects, there were 125 subjects with peptic ulcer (77 with gastric ulcer and 48 with duodenal ulcer). The male/female ratio, mean age and $H$. pylori-positive rate were significantly higher in the peptic ulcer group than those in the non-ulcer group. Strong allelic associations were recognized among 3 polymorphisms as reported previously (12). The most frequent haplotype was $-686 \mathrm{G} /-684 \mathrm{G} /-650 \mathrm{C}$. The -686/-684 G/A genotype was not detected.

The association between Nrf2 promoter polymorphisms and peptic ulcer. By the unadjusted analysis, male gender, $H$. pylori infection, $-686 /-684 \mathrm{G} / \mathrm{G}$ and $-650 \mathrm{C}$ carriers were significantly associated with the increased risk, whereas the -686/-684 AG/AG homozygote genotype was associated with a significantly reduced risk for the development of peptic ulcer, especially gastric ulcer (Table II). On the other hand, infection with $H$. pylori and male gender were significantly associated with a risk for developing duodenal ulcer, whereas Nrf2 promoter polymorphisms were not.

By the analysis after adjustment for age, gender, NSAID/ aspirin use and $H$. pylori infection status, the $-686 /-684 \mathrm{~A} / \mathrm{G}$ homozygote genotype was linked to a significantly reduced risk for developing peptic ulcer (OR, 0.35; 95\% CI, 0.16$0.79 ; \mathrm{p}=0.011)$, especially gastric ulcer $(\mathrm{OR}, 0.25 ; 95 \% \mathrm{CI}$, 0.088-0.73; p=0.011; Table III).

The association between the -686/-684 A/G allele and the updated Sydney system scores. The association between the $-686 /-684$ A/G allele and the updated Sydney system score is shown in Fig. 1. Analysis was performed in 231 subjects whose scores were able to be assessed. The activity and inflammation scores in Nrf2 -686/-684 A/G carriers were significantly lower than those in the non-A/G carriers $(\mathrm{p}=0.0085$ and $\mathrm{p}=0.025$, respectively). 
Table I. Characteristics of the subjects and frequency of genotypes.

\begin{tabular}{|c|c|c|c|c|}
\hline & Non-ulcer & Peptic ulcer & Gastric ulcer & Duodenal ulcer \\
\hline Number of subjects & 259 & 125 & 77 & 48 \\
\hline Mean age \pm SD (years) & $50.4 \pm 20.3$ & $62.9 \pm 14.2^{\mathrm{a}}$ & $66.7 \pm 12.4$ & $56.8 \pm 14.8$ \\
\hline Male:female & 139:120 & $99: 26^{\mathrm{a}}$ & $60: 17$ & $39: 9$ \\
\hline H. pylori-positive rate & $61.3 \%$ & $88.0 \% \mathrm{a}^{\mathrm{a}}$ & $88.3 \%$ & $87.5 \%$ \\
\hline \multicolumn{5}{|l|}{$-686 /-684$ genotype } \\
\hline GG/GG & 91 & 44 & 27 & 17 \\
\hline $\mathrm{GG} / \mathrm{AG}$ & 96 & 54 & 36 & 18 \\
\hline GG/AA & 2 & 7 & 3 & 4 \\
\hline $\mathrm{AG} / \mathrm{AG}$ & 55 & 11 & 5 & 6 \\
\hline AG/AA & 10 & 7 & 4 & 3 \\
\hline$-686 \mathrm{~A}$ allele frequency & $44.9 \%$ & $39.4 \%$ & $38.0 \%$ & $41.7 \%$ \\
\hline$-684 \mathrm{~A}$ allele frequency & $2.7 \%$ & $5.7 \%$ & $4.7 \%$ & $7.3 \%$ \\
\hline \multicolumn{5}{|l|}{-650 genotype } \\
\hline $\mathrm{C} / \mathrm{C}$ & 129 & 70 & 39 & 31 \\
\hline $\mathrm{C} / \mathrm{A}$ & 111 & 53 & 38 & 15 \\
\hline $\mathrm{A} / \mathrm{A}$ & 19 & 2 & 0 & 2 \\
\hline$-650 \mathrm{~A}$ allele frequency & $28.8 \%$ & $22.8 \%$ & $24.7 \%$ & $19.8 \%$ \\
\hline
\end{tabular}

${ }^{\mathrm{a}} \mathrm{p}<0.0001$ vs. non-ulcer.

Table II. Association between gastro-duodenal ulcer and various risk factors.

\begin{tabular}{|c|c|c|c|}
\hline \multirow[b]{2}{*}{ Variables } & \multicolumn{3}{|c|}{ OR ( $95 \%$ confidence intervals) } \\
\hline & Peptic ulcer & Gastric ulcer & Duodenal ulcer \\
\hline$-686 /-684$ G/G carrier & $2.01(1.13-3.56)^{a}$ & $2.52(1.19-5.45)^{f}$ & $1.49(0.69-3.24)$ \\
\hline$-686 /-684$ A/G homozygote & $0.36(0.18-0.71)^{b}$ & $0.26(0.099-0.67)^{\mathrm{g}}$ & $0.52(0.21-1.28)$ \\
\hline$-650 \mathrm{C}$ carrier & $4.87(1.12-21.2)^{c}$ & - & $1.84(0.97-3.48)$ \\
\hline Male gender & $3.29(2.00-5.40)^{d}$ & $3.05(1.69-5.50)^{h}$ & $3.74(1.74-8.04)^{j}$ \\
\hline NSAID/aspirin use & $1.21(0.58-2.53)$ & $1.64(0.74-3.63)$ & $0.59(0.17-2.11)$ \\
\hline H. pylori infected & $4.62(2.47-8.63)^{\mathrm{e}}$ & $4.76(2.22-10.2)^{i}$ & $4.41(1.77-11.0)^{\mathrm{k}}$ \\
\hline
\end{tabular}

By unadjusted analysis. ${ }^{\mathrm{a}} \mathrm{p}=0.017,{ }^{\mathrm{b}} \mathrm{p}=0.0032,{ }^{\mathrm{c}} \mathrm{p}=0.035,{ }^{\mathrm{d}} \mathrm{p}<0.0001,{ }^{\mathrm{e}} \mathrm{p}<0.0001,{ }^{\mathrm{f}} \mathrm{p}=0.016,{ }^{\mathrm{g}} \mathrm{p}=0.0055,{ }^{\mathrm{h}} \mathrm{p}=0.0002,{ }^{\mathrm{i}} \mathrm{p}<0.0001,{ }^{\mathrm{j}} \mathrm{p}=0.0007$, and ${ }^{\mathrm{k}} \mathrm{p}=0.0014$.

Table III. The risk of Nrf2 promoter polymorphisms for gastro-duodenal ulcer.

\begin{tabular}{|c|c|c|c|}
\hline \multirow[b]{2}{*}{ Variables } & \multicolumn{3}{|c|}{ OR ( $95 \%$ confidence intervals) } \\
\hline & Peptic ulcer & Gastric ulcer & Duodenal ulcer \\
\hline$-686 /-684 \mathrm{G} / \mathrm{G}$ carrier & $1.37(0.68-2.75)$ & $1.85(0.77-4.41)$ & $0.95(0.38-2.35)$ \\
\hline$-686 /-684$ A/G homozygote & $0.35(0.16-0.79)^{\mathrm{a}}$ & $0.25(0.088-0.73)^{b}$ & $0.59(0.21-1.67)$ \\
\hline$-650 \mathrm{C}$ carrier & $3.77(0.73-19.5)$ & - & $1.42(0.27-7.62)$ \\
\hline
\end{tabular}

By logistic regression analysis after adjustment for age, gender, NSAID/aspirin use and $H$. pylori infection status. ${ }^{\mathrm{a}} \mathrm{p}=0.011$ and ${ }^{\mathrm{b}} \mathrm{p}=0.011$. 


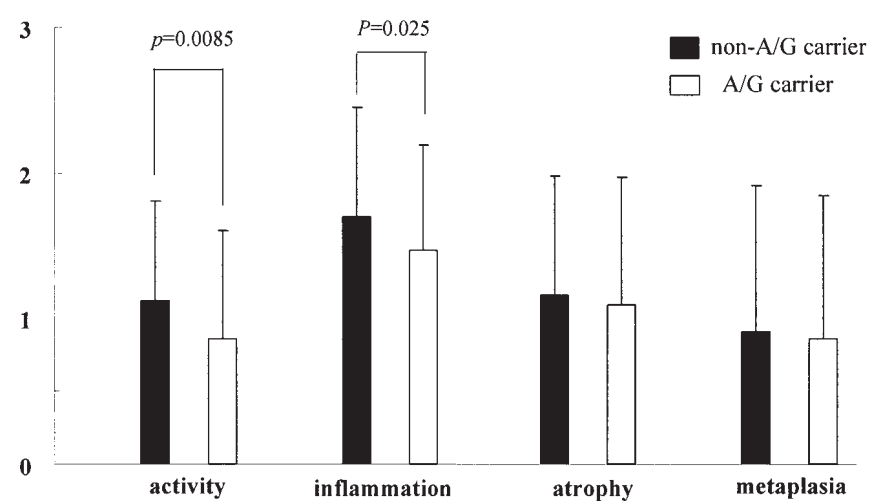

Figure 1. The association between the $-686 /-684 \mathrm{~A} / \mathrm{G}$ allele and the updated Sydney system score. The comparison between two groups was performed by the Mann Whitney U-test. Both activity and inflammation scores in $\mathrm{A} / \mathrm{G}$ carriers were significantly lower than those in non-A/G carriers.

\section{Discussion}

Results from our study suggested that the polymorphisms of the Nrf2 gene promoter were significantly associated with a risk for the development of peptic ulcer, especially gastric ulcer. It was previously reported that the A allele frequencies at positions $-686,-684$, and -650 were respectively $42.6,4.3$, and $31.5 \%$ in healthy controls (8). In our study, all subjects underwent endoscopic examination and manifested upper gastro-duodenal symptoms, with the $H$. pylori-positive rate being high in both the peptic ulcer and non-ulcer group. The reason why we found a lower frequency of the $-650 \mathrm{~A}$ allele may be that this study was not performed in a healthy population.

Nrf2 is an important regulator of genes induced by oxidative stress (5) and various pathological features, some of which are similar or related to human disorders, are seen in Nrf2-deficient mice (14-17). Thus, there is no doubt that Nrf2 plays an important role in the elimination of ROS. In C57BL/6J mice, a strain sensitive to hyperoxic stress, an SNP was detected in the promoter region of the nrf2 gene (6). In human disorders, we reported that the Nrf2-686G and $-650 \mathrm{C}$ alleles were associated with infiltration of inflammatory cells into the gastric mucosa, either independently or by interacting with $H$. pylori infection (11). In addition, we also revealed that the $-686 /-684 \mathrm{~A} / \mathrm{G}$ haplotype was significantly associated with the susceptibility to ulcerative colitis (18). On the basis of these facts, we suspect that Nrf2 promoter polymorphisms may influence inflammatory conditions by altering the activity of the gene product, although it has not been clarified how polymorphisms influence the activity and expression of Nrf2 for which we obtained no evidence.

In our previous study, we found no significant association of single nucleotide polymorphism at a position -686 or -650 with peptic ulcer diseases (11). Therefore, we investigated the relationship between the -686/-684 haplotype and peptic ulcers in this study. As a result, it was clarified that the $-686 /$ $-684 \mathrm{G} / \mathrm{G}$ allele was associated with an increased risk and the $\mathrm{A} / \mathrm{G}$ allele was linked to a reduced risk for the development of gastric ulcer. Furthermore, there were fewer inflammatory cells infiltrated into gastric mucosa in -686/-684 A/G allele carriers than non-carriers. These facts suggest that the variation of the Nrf2 -686/-684 haplotype is one of the regulatory factors for the severity of gastric mucosal inflammation and the development of gastric ulcer. After age, gender, H. pylori infection and NSAID/aspirin use were controlled, there was a significant association between the $-686 /-684 \mathrm{~A} / \mathrm{G}$ homozygote and the reduced risk for developing gastric ulcer. That is, the Nrf2 -686/-684 haplotype was thought to be an independent factor in the pathogenesis of gastric ulcer. Gastric and duodenal ulcers share many features in terms of pathogenesis, diagnosis, and treatment, but several factors distinguish the two. The exact mechanism of the formation of peptic ulcers is beyond the scope of this study. However, the effects of the Nrf2 gene polymorphism on the formation of peptic ulcers were thought to depend on whether the ulcer occurs in the stomach or in the duodenum.

In conclusion, the $-686 /-684 \mathrm{G} / \mathrm{G}$ and $-650 \mathrm{C}$ alleles of the Nrf2 gene promoter are suggested to be associated with the development of gastric ulcer, whereas the $-686 /-684$ A/G genotype is linked to a reduced risk for developing gastric ulcer.

\section{Acknowledgements}

This study was supported, in part, by a Grant-in-Aid for the 21st Century Center of Excellence Program of Fujita Health University from the Ministry of Education, Culture, Sports, Science, and Technology of Japan.

\section{References}

1. Naito Y and Yoshikawa T: Molecular and cellular mechanisms involved in Helicobacter pylori-induced inflammation and oxidative stress. Free Radic Biol Med 33: 323-336, 2002.

2. Burdon RH: Superoxide and hydrogen peroxide in relation to mammalian cell proliferation. Free Radic Biol Med 18: 775-794, 1995.

3. Suzuki H, Miura S, Imaeda H, et al: Enhanced levels of chemiluminescence and platelet activating factor in urease-positive gastric ulcer. Free Radic Biol Med 20: 449-454, 1996.

4. Davies GR, Simmonds NJ, Stevens TRJ, et al: Helicobacter pylori stimulates antral mucosal reactive oxygen metabolite production in vivo. Gut 35: 179-185, 1994.

5. Ishii $\mathrm{T}$, Itoh $\mathrm{K}$, Takahashi $\mathrm{S}$, et al: Transcription factor Nrf2 coordinately regulates a group of oxidative stress-inducible genes in macrophages. J Biol Chem 275: 16023-16029, 2000.

6. Cho HY, Jedlicka AE, Reddy SP, Zhang LY, Kensler TW and Kleeberger SR: Linkage analysis of susceptibility to hyperoxia. Nrf2 is a candidate gene. Am J Respir Cell Mol Biol 26: 42-51, 2002.

7. Hirayama A, Yoh K, Nagase S, et al: EPR imaging of reducing activity in Nrf2 transcription factor-deficient mice. Free Radic Biol Med 34: 1236-1242, 2003.

8. Yamamoto $\mathrm{T}$, Yoh K, Kobayashi A, et al: Identification of polymorphisms in the promoter region of the human NRF2 gene. Biochem Biophys Res Commun 321: 72-79, 2004.

9. Wolfe MM, Lichtenstein DR and Singh G: Gastrointestinal toxicity of nonsteroidal antiinflammatory drugs. N Engl J Med 340: 1888-1899, 1999.

10. Bodger K and Crabtree JE: Helicobacter pylori and gastric inflammation. Br Med Bull 54: 139-150, 1998.

11. Arisawa T, Tahara T, Shibata T, et al: The relationship between Helicobacter pylori infection and promoter polymorphism of the Nrf2 gene in chronic gastritis. Int J Mol Med 19: 143-148, 2007.

12. Dixon MF, Genta RM, Yardley JH and Correa P: Classification and grading of gastritis: the updated Sydney system. Am J Surg Pathol 20: 1161-1181, 1996. 
13. Arisawa T, Tahara T, Shibata T, et al: A polymorphism of microRNA 27 a genome region is associated with the development of gastric mucosal atrophy in Japanese male subjects. Dig Dis Sci 52: 1691-1697, 2007.

14. Chan K and Kan YW: Nrf2 is essential for protection against acute pulmonary injury in mice. Proc Natl Acad Sci USA 96: 12731-12736, 1999.

15. Enomoto A, Itoh K, Nagayoshi E, et al: High sensitivity of Nrf2 knockout mice to acetaminophen hepatotoxicity associated with decreased expression of ARE-regulated drug metabolizing enzymes and antioxidant genes. Toxicol Sci 59: 169-177, 2001.
16. Aoki Y, Sato H, Nishimura N, Takahashi S, Itoh K and Yamamoto M: Accelerated DNA adduct formation in the lung of the Nrf2 knockout mouse exposed to diesel exhaust. Toxicol Appl Pharmacol 173: 154-160, 2001.

17. Ramos-Gomez M, Kwak MK, Dolan PM, et al: Sensitivity to carcinogenesis is increased and chemoprotective efficacy of enzyme inducers is lost in nrf2 transcription factor-deficient mice. Proc Natl Acad Sci USA 98: 3410-3415, 2001.

18. Arisawa T, Tahara T, Shibata T, et al: Nrf2 gene promoter polymorphism is associated with ulcerative colitis in Japanese population. Hepato-gastroenterology (In press). 